\title{
RASPAGENS DAS PALHETAS POR OBOÍSTAS BRASILEIROS \\ - UM ESTUDO DOS AJUSTES NAS PALHETAS DE OBOÉ SOB AÇÃO DE AGENTES CLIMÁTICOS EXTERNOS
}

\section{SCRAPING OF REEDS BY BRAZILIAN OBOIST - A STUDY OF THE ADJUSTMENTS IN THE OBOE REEDS UNDER THE ACTION OF EXTERNAL CLIMATIC AGENTS}

\author{
Joel Gisiger \\ Universidade Federal da Bahia \\ joelgisiger@hotmail.com
}

\section{Resumo}

A presente pesquisa visa observar e identificar os ajustes propostos por oboístas brasileiros em palhetas de oboé preparadas para a performance e que sofrem alterações devido à ação da umidade do ar, temperatura do ambiente e altitude relativa ao nível do mar. Também foram investigadas possiveis tendências nas preferências de sonoridade e flexibilidade dos oboístas entrevistados, procurando compreender se existe algum fator que ligue tais tendências com os tipos de ajustes propostos. Com a finalidade de direcionar a pesquisa a um foco de interesse comum aos entrevistados, dentre as várias escolas de raspado, optou-se por duas: Escola Alemã e Escola Americana, tendo em vista que elas exercem grande influência nos mais diversos estilos de raspagem. Um notório fenômeno brasileiro também foi investigado: a convivência pacífica das diferentes escolas dentro das orquestras. Como parte dos procedimentos metodológicos, foi realizado um breve levantamento bibliográfico de autores discorrendo sobre raspagens de palhetas de oboé, com a finalidade de compreender o que se considera uma palheta pronta para performance e o que a caracteriza. Utilizou-se também a ferramenta de pesquisas on-line survey mokey para uma investigação com oboístas brasileiros, mediante a observação das tendências de sonoridade, flexibilidade e ajustes da palheta. Após a análise dos dados, houve uma listagem graduada de ajustes classificada pelos oboístas brasileiros dentro de suas escolas de raspagem. Concluiu-se haver características muito semelhantes nas preferências de sonoridade, 
flexibilidade e ajustes, apontando uma provável causa que aproxima as diferentes escolas de oboé em território nacional.

Palavras-chave: oboé; palhetas; ajustes; variações climáticas; escola alemã; escola americana.

\section{Abstract}

The present research aims to observe and identify the adjustments proposed by Brazilian oboists on oboe reeds prepared for the performance and which suffer changes due to the action of air humidity, temperature and altitude relative to sea level. Possible tendencies in the preferences of sonority and flexibility of the oboists interviewed were also investigated, trying to understand if there was any factor connecting such tendencies with the types of adjustments proposed. In order to direct the research to a focus of common interest to the interviews, we summarized the different schools of scraping in two: German School and American School, considering that these schools exert great influence in the most diverse styles of scraping. A notorious Brazilian phenomenon was also investigated, which is the peaceful coexistence of the different schools within the orchestras. As part of the methodological procedures, a brief bibliographic survey of authors discussing oboe scraping was carried out, in order to understand what is considered a ready prepared reed for a performance and what characterizes it. The online survey tool "survey mokey" was also used for an investigation with Brazilian oboists, observing the tendencies of sonority, flexibility and adjustments of the reed. After analyzing the data, there was a graduated list of adjustments classified by the Brazilian oboists within their scraping schools. It was concluded that there are very similar characteristics in the preferences of sonority, flexibility and adjustments, pointing to a probable cause that approaches the different schools of oboe in national territory.

Keywords: oboe; reeds; adjustments; climatic variations; german school; american school. 


\section{Lista de figuras}

Gráfico 1: Timbre, Flexibilidade e Volume Sonoro numa situação de concerto.

Fonte: Elaborado pelo autor, criados pelo programa de pesquisa on-line, survey $\mathrm{C}$.

Gráfico 2: Sonoridade versus conforto em situação de repertório (A expressão "palheta que toque bem sugerindo sensação de conforto').

Fonte: Elaborado pelo autor, criados pelo programa de pesquisa on-line, survey monkey.

Gráfico 3: Escolha da palheta para uma determinada função.

Fonte: Elaborado pelo autor, criados pelo programa de pesquisa on-line, survey monkey.

Gráfico 4: Escolha da palheta para repertório específico. Listagem por ordem das preferências de características quanto à flexibilidade, dinâmica e timbre.

Fonte: Elaborado pelo autor, criados pelo programa de pesquisa on-line, survey monkey.

Gráfico 5: Preparo de uma palheta para repertório específico.

Fonte: Elaborado pelo autor, criados pelo programa de pesquisa on-line, survey monkey.

Gráfico 6: Ajustes de raspagem visando contornar problemas de flexibilidade.

Fonte: Elaborado pelo autor, criados pelo programa de pesquisa on-line, survey monkey.

Gráfico 7: Ajustes de raspagem visando contornar problemas interpretativos.

Fonte: Elaborado pelo autor, criados pelo programa de pesquisa on-line, survey monkey.

Gráfico 8: Ajustes de raspagem visando contornar problemas causados pela pressão atmosférica.

Fonte: Elaborado pelo autor, criados pelo programa de pesquisa on-line, survey monkey.

Gráfico 9: Ajustes de raspagem visando contornar problemas causados por fatores climáticos.

Fonte: Elaborado pelo autor, criados pelo programa de pesquisa on-line, survey monkey. 


\section{Introdução}

A seguir uma breve explanação envolvendo o métier de um oboísta e seu contexto no cenário orquestral contemporâneo no Brasil. Propõe-se então, através dessas elucidações, uma preparação para os assuntos que aqui serão abordados.

\section{A relevância para o oboísta de ter uma palheta que reaja com precisão às suas propostas interpretativas}

Para um oboísta seriamente comprometido com sua profissão, normalmente existe uma grande sensação de insegurança no domínio de seu instrumento ao se deparar com uma palheta que muda subitamente de atitude no momento da execução de uma obra previamente ensaiada. Blasco-Yepes e Payri comentam em seu artigo que: "A manufatura da palheta pode, portanto, influenciar a habilidade técnica para alcançar alguns requerimentos técnicos e influenciará a performance em geral $[\ldots]^{1 "}(2010$, p. 7$)$.

Observa-se que o estilo de tocar de um oboísta depende completamente de sua palheta para que sua expressividade seja plenamente manifestada. Ele, muitas vezes não conseguirá interpretar tão bem uma determinada passagem, caso sua palheta não reproduza com perfeição aquilo que está sendo proposto.

\section{Uma complexidade: não há uma palheta igual à outra}

Uma palheta de oboé muda constantemente de atitude e, por isso, necessita de ajustes, muitas vezes, sutis. Isso ocorre devido às características naturais da cana, planta com a qual é manufaturada, conhecida por Arundo Donax, questão essa que será abordada mais adiante. Por hora, será mantida uma breve análise na relação palhetainstrumento-indivíduo.

I Reed making may therefore influence the technical ability to achieve some technical requirements and will influence the global performance [... ]. (tradução nossa) 
Vários fatores influenciam sua manufatura. Entre esses, podemos apontar alguns como: a maneira de assoprar dos oboístas é pessoal, existindo variações na velocidade do ar; o formato da embocadura varia de acordo com o instrumentista; e, por fim, cada instrumento oferece características de afinação e resistência que vão interferir na maneira de ajustar a terminação de uma palheta.

De acordo com Ledet, essas sutilezas de ajustes são compreendidas através de um complexo sistema de observação de causa e efeito, ação e reação. É uma arte centenária repassada pelo professor e que deve ser readaptada por cada aluno. Para que isso ocorra, o aluno deve ter conhecimento de suas próprias necessidades em relação ao seu instrumento, para então, definir como uma palheta deverá ser ajustada. Isso acaba por interferir no desenho do raspado e nas medidas finais, bem como na escolha adequada do material utilizado para montar uma palheta. Deve-se levar em conta também: estilos de moldes, diferentes formatos dos tubos, tipo de material empregado na construção desses, além das medidas de diâmetro da cana empregada, sua dureza, sua densidade e sua goivagem. Mediante a união de todos esses fatores é que surgem os diferentes tipos de raspagens e escolas, das quais predominam o raspado curto e o raspado longo, ou no jargão dos oboístas no Brasil, a palheta alemã e a palheta americana, respectivamente. Como podemos observar:

[...] fatores pertinentes para a produção do som no oboé são discutidos [...] como ajuda para que se entenda totalmente o porquê de existir diferentes estilos de palheta de oboé e quais são esses estilos. A respiração, a articulação, a embocadura, o instrumento, a acústica e o efeito do ouvinte sobre o instrumentista influenciam os estilos de palheta globalmente, bem como as mínimas alterações da palheta que um artista faz para atingir um timbre ou uma resposta. Quando se vê um oboísta tirando a sua palheta de oboé e cuidadosamente fazer uma sequência de manejos de faca em certas partes da palheta, ele está observando uma operação antiga. Oboísta está exercitando sua habilidade de adaptar a palheta o mais próximo para o seu próprio método de produção de som $e$ às suas necessidades.

$\bigcirc$ método de produção de som do instrumentista - como ele respira, seu estilo de articulação, o tipo e o uso de sua embocadura, etc. - irá afetar o timbre e a resposta 
da palheta $e$, consequentemente, afetará suas medidas $e$, portanto, sua forma visual [...] ${ }^{2}$ (LEDET, 2008, p. xv e xvi).

De acordo com o autor, então, cada palheta se tornará uma peça única, particular. Portanto, devido à natureza mutável da cana, a relação entre instrumento e indivíduo é intrínseca, mas é exatamente essa relação que vai levar o oboísta a realizar suas tendências e anseios interpretativos, suas características de qualidade sonora e também a afinação do instrumento na qual ela deverá interagir vibrando.

\section{O oboísta e seu ambiente de trabalho}

Quando a vibração de uma palheta se altera, surgem dificuldades de articulação, dinâmica, afinação e na emissão de certas notas, especialmente na região grave do oboé. A habilidade performática do oboísta, então, é colocada à prova e podem ocorrer mudanças inesperadas em relação ao que a partitura propõe ou ao que se ensaiou anteriormente. Ceralmente, problemas acontecem para aqueles que deixam de trabalhar adequadamente suas palhetas, ao procurar que elas vibrem de maneira correta sem os devidos ajustes. Há quem, por exemplo, ao optar por uma sonoridade robusta, faz uma palheta com menor capacidade de vibração, mas com timbre recheado de harmônicos graves, obtendo uma sonoridade grande, mas com pouca flexibilidade, o que pode comprometer sua performance.

A falta de zelo prévio com os cuidados necessários leva o oboísta, muitas vezes, a driblar situações repentinas de desconforto, optando em alterar a execução da dinâmica e da articulação escrita na peça,

$2[\ldots]$ factors pertinent to the production of tone on the oboe are discussed [...] as an aid to understanding fully why oboe reed styles exist and what these styles are. Respiration, articulation, embouchure, instrument, acoustics, and the effect of the listener on the player influence overall reed styles as well as the minute alterations of the reed that an artistperformer makes in order to achieve a certain timbre or response. When on sees an oboist remove the reed from the oboe and carefully make few strokes of the knife on certain parts of the reed, he is observing an age-old operation. The oboist is exercising his ability to suit the reed more to his method of tone production and playing needs.

The player's method of tone production - the way he breathes, his style of articulation, the type and use of his embouchure, etc. - will affect the timbre and response of the reed and will, consequently, affect its measurements and, therefore, its visual form. [... ]. (tradução nossa) 
facilitando, dessa maneira, a sua performance ao tocar tudo mais forte e com menos ênfase nas dinâmicas e ataques. Nesse caso, a sustentação de uma sonoridade constante e forte advém de uma maior pressão do ar para conseguir a emissão das notas, pois ao assoprar menos, a palheta não responde e cessa de vibrar. Ao agir assim, podem não se comprometer profissionalmente com os demais colegas de orquestra ou grupo de câmara, mas fica comprometida a arte de se fazer música.

De acordo com o célebre oboísta inglês Leon Cossens, "a palheta está para o oboísta assim como a garganta está para o cantor" (COSSENS; ROXBURGH, 1977, p. 55). Ele sugere, então, que haja um maior controle da palheta como se ela fosse algo intrínseco ao organismo humano. Outro instrumentista, o fagotista Edwin Lacy, nos ajuda a entender que a palheta deve servir ao invés de fazer o papel de mestre:

Em primeiro lugar, meu professor Sr. Leonard Sharrow, cuja técnica de fazer palhetas é talvez menos carregada de misticismo do que muitos outros, inicialmente levou-me a considerar a cana e a palheta como minhas servas ao invés de meus mestres. ${ }^{4}$ (1988).

Por hora, esses exemplos atestam que o oboísta deve buscar o domínio total de sua palheta, sem o qual ficará impossibilitado de exercer sua profissão corretamente. Desse modo, concluímos que se faz necessário um contínuo aprofundamento de uma percepção clara dos vários fatores externos que podem afetar a vibração da palheta e, consequentemente, reagir com 0 intuito de solucionar os problemas encontrados.

3 Das Rohrblatt der Oboe ist das, was der Kehlkopf für die menschliche Stimme ist. (tradução nossa)

4 First, my teacher, Mr. Leonard Sharrow, whose reed-making technique is perhaps less burdened with mysticism than that of many others, initially led me to regard the cane and the reed as my servant rather than my master. 


\section{Breve comentário sobre o cenário nacional e a metodologia de ajustes}

A palheta é parte fundamental do instrumento. Tão importante quanto estudar oboé, faz parte também, na formação desse profissional, aprender a sua manufatura. Como dito anteriormente, essa arte costumou ser repassada, ao longo do tempo, pelo professor, demorando muito para aparecer um manual metodológico com suas instruções detalhadas. No Brasil, não foi diferente e a manufatura das palhetas e seus ajustes, por vezes, ainda são passados sob a forma oral e pela imitação de gestos, sem o apoio de métodos. Esses costumes antigos são citados por Blasco-Yepes e Payri:

Apesar da conhecida importância da palheta, precisamos esperar até o Século XIX para encontrar as primeiras instruções detalhadas de como se faz uma palheta, e nós podemos deduzir que dantes elas eram transmitidas através de comunicação oral ou de imitações gestuais.. (BURCESS; HAYNES, 2004 apud BLASCO-YEPES; PAYRI, 2010, p. 1)

Falta, no Brasil, a existência de uma bibliografia com autor nacional que aborde a confecção de palhetas de oboé, o que leva o estudante a recorrer ao material existente no estrangeiro, traduções, brochuras improvisadas ou a tradição passada de forma oral na relação professor-aluno.

\section{A cana Arundo Donax}

Os fatores que modificam as vibrações da palheta de oboé provêm da própria natureza orgânica da cana que se altera quando submetida à ação de agentes externos. Conforme a pesquisa realizada por Blais:

5 In spite of the well-known importance of the reed, we must wait until the XIXth century to find the first detailed written instructions on how to make a reed, and we may deduct that previously they were transmitted through oral communication and through handicrafts imitation. (tradução nossa) 
Tanto com cana pré-processada quanto com palhetas concluídas, a inconsistência é um problema. Como qualquer instrumentista de palheta dupla sabe pequenas mudanças no clima, umidade e temperatura podem causar mudanças significativas na qualidade de uma palheta; e como sabem aqueles que fazem palhetas, a própria cana é um material altamente variável por causa de sua natureza orgânica. ${ }^{6}$ (2011, p. 9-10)

Esses agentes são conhecidos por causarem alterações nas fibras da cana. Para melhor compreensão do processo que altera o comportamento da palheta, se faz necessário uma breve explanação sobre o material com o qual ela é construida.

A matéria prima principal para a manufatura de uma palheta provém de certo tipo de gramínea cujo nome em botânica é Arundo Donax. No Brasil, essa variedade é conhecida como Cana do Reino ou Taquara do Reino.

John Backus explica que a Arundo Donax é utilizada para as palhetas de instrumentos de sopro, pois é uma planta que combina alta elasticidade com pouca densidade, além de produzir uma sonoridade agradável. Seu tempo de uso é bastante limitado, e por ser de origem vegetal, possui uma série de ações imprevisíveis.

Instrumentos de sopro que incluem o clarinete, oboé e fagote, são animados por uma palheta onde tradicionalmente é usado como material uma cana que cresce naturalmente, identificada pelo nome botânico Arundo Donax. Esse material tem as características desejáveis de alto módulo de elasticidade combinada com uma baixa densidade (grifo nosso). As tentativas de fazer palhetas de instrumento de sopro de materiais sintéticos não tiveram qualquer grau de sucesso devido ao fato de que não foi possível simular com proximidade um junco sintético que tenha as características desejáveis de uma palheta. A cana natural, enquanto proporciona as características tonais

6 Both with pre-processed cane and completed reeds, inconsistency is a significant problem. As any double reed player knows, slight changes in weather, humidity, and temperature can cause significant changes in the quality of a reed; and, as reedmakers know, cane itself is a highly variable material because of its organic nature. (tradução nossa) 
desejadas, tem um número de desvantagens. Em primeiro lugar, tal material natural tem uma vida muito limitada. Além disso, como é o caso para materiais mais naturais, é difícil fornecer uma previsão aproximada das características que se aproxime dos trejeitos de um junco natural (grifo nosso), e, portanto, algum cuidado deve ser tomado na escolha e fabricação de tais palhetas para garantir que eles tenham as características desejadas. As características desejáveis de uma cana usada como material podem ser entendidas quando se considera o clarinete ou outro instrumento de sopro no conjunto com sua palheta? (BACKUS, 1982, s/n)

É esta característica da Arundo Donax que determina seu uso na manufatura de palhetas, pois se por um lado as inconstantes ações imprevisíveis da cana são identificadas como sendo um fator que atrapalha, por outro lado, são determinantes para que um resultado desejado de boa vibração possa ser alcançado. Efetivamente, só um trabalho sobre essas mesmas ações imprevisiveis através de experiência pessoal somada ao uso de ferramentas apropriadas, para poder determinar a vibração correta da palheta de acordo com o instrumento para o qual ela será concebida. Ou seja, devido à elasticidade da cana, essa poderá inchar ou desinchar, dependendo da umidade existente no ambiente, porém as fibras estreitas mantêm a estrutura da cana com suas proporções de dureza. A combinação desses fatores que, a princípio, parecem conflitantes entre si, devem ser compreendidos e controlados, e assim (e somente assim), serão usados a favor da obtenção de uma palheta que vibre de maneira correta. Portanto, usar das próprias características de instabilidade da cana se faz necessário para poder modificá-la adequadamente.

\footnotetext{
7 Reed excited woodwind instruments which include the clarinet, oboe, and bassoon, traditionally use for their reed material a naturally growing cane identified by the botanical name Arundo Donax. This material has the desirable characteristics of high modulus of elasticity combined with a low density. Attempts to make woodwind instrument reeds from synthetic materials have not had any great degree of success due to the fact that it has not been possible to closely simulate in such a synthetic reed the desirable characteristics of the natural reed. The natural reed, while providing the desired tonal characteristics, has a number of disadvantages. First, such natural reed material has a very limited life. Further, as is true for most natural materials, it is difficult to provide close predictability as to the characteristics of natural reeds, and therefore some care must be taken in the choice and fabrication of such reeds to assure that they have the desired characteristics. The desirable characteristics of a reed material may be understood by considering the clarinet or other woodwind instrument together with its reed. (tradução nossa)
} 


\section{Fatores do meio ambiente}

As palhetas de oboé e dos demais instrumentos de sopro que delas dependem, sofrem alterações de acordo com a ação de fatores provenientes do meio-ambiente que interagem com as fibras da cana que as compõem. Esses fatores são a umidade do ar, a altitude, a temperatura ambiente, a pressão barométrica e a acústica local. Elisabeth Young Ann Rennick comenta em seu artigo Young Rennick, a ligação intrínseca de algumas dessas variáveis com o ajuste das palhetas:

Os fabricantes de palhetas, conscientemente ou inconscientemente, consideram muitas variáveis além do pedaço de cana ao tentar fazer esta peça de madeira vibrar. A umidade, a altitude e a pressão barométrica afetam o desempenho de uma palheta e as decisões sobre como raspá-la. Todos os três dos fatores mencionados estão ligados [...] todos esses fatores ambientais afetam muito as vibrações de uma cana $[. . .]^{8}$ (2010, p. 38).

Esses elementos se alteram, passando a agir com maior ou menor intensidade devido à ação dos fenômenos da natureza, como a ação do sol, aparecimento de nuvens, ventos, chuvas entre outros. A ação do homem também altera a escala de valores dos elementos supracitados, quando se utiliza de aparelhos de ar condicionado, aquecedores de ar e umidificadores de ar para o controle da temperatura ou microclima em ambientes fechados. A combinação dos valores de todos esses elementos citados, quando medidos por aparelhos especializados, quase nunca terá a mesma configuração, pois cada elemento interage de forma diferente quando estimulado por ações da natureza ou ações produzidas por aparelhos criados pelo homem. Além dessas ações excitadoras, quer naturais ou artificiais, ainda há

8 Reed-makers either consciously or unconsciously consider many variables in addition to the piece of cane when attempting to make this piece of wood vibrate. Humidity, altitude, and barometric pressure all affect the performance of a reed and factor into decisions about how to scrape it. All three of the above mentioned factors are linked. As you travel in an area of higher altitude, atmospheric or barometric pressure decreases and you are likely to experience less humidity. Although all of these environmental factors greatly affect the vibrations of a reed, this survey reveals na obvious hierarchy in the amount of conscious thought given to each concept. (tradução nossa) 
a ação do tempo diário, ou seja, no decorrer das horas os valores se alteram e, consequentemente, nosso objeto de estudo, a palheta, muda significativamente.

\section{Acústica}

De acordo com Ledet, a acústica é outro fator que interfere na vibração da palheta de oboé. Ela também sofre interferências quando utilizada em ambientes ou localidades diferentes e pode mudar de um minuto para o outro, como por exemplo, quando o oboísta toca seu instrumento nos camarins de um teatro e logo em seguida dentro da sala de concertos. Por isso, é comum ver um oboísta ajeitando sua palheta no palco antes das apresentações, e de preferência, com as mesmas configurações de acústica, luz e ar condicionado que serão utilizados no momento do concerto.

Depois da palheta e do oboé, o mais notável fator que influencia o instrumentista é, provavelmente, a quantidade de reverberação da sala. A propriedade acústica da sala afeta o balanço do som que é emitido pelo instrumentista, pela palheta e pelo instrumento, e pede que o instrumentista faça ajustes em sua palheta. ${ }^{9}$ (2008, p. 5 I).

Em outro trecho lemos:

Admitidamente, enquanto o oboísta estiver tocando, é duvidoso que ele tenha um real e seleto controle sobre algum fenômeno acústico. Mas, ele pode reconhecer a presença deles e, por meio disso, talvez estimular uma maior ressonância em determinadas áreas, através da

9 After the reed and the oboe, the most noticeable single factor that influences the player is probably the reverberation rate of the room. The acoustical properties of the room affect the balance that is given to the tone by the player, the reed, and the instrument and can cause the player to make adjustments of his reed. (tradução nossa) 
modificação de sua palheta e de sua emissão sonora ${ }^{10}$ (2008, p. 41 ).

Ao tocarmos numa sala de concerto cuja acústica é muito viva, percebe-se uma dificuldade em controlar as parciais dos harmônicos agudos, e o oboé passa a soar de uma forma muito estridente. Tomemos aqui a liberdade em citar a acústica da Sala São Paulo, sede da OSESP. A Sala São Paulo notoriamente é uma sala de concertos considerada "viva", ou seja, possui uma acústica com muita reverberação, onde as parciais graves são deficitárias, prevalecendo às parciais agudas. Isso resulta que, para alguns instrumentos, exista uma prevalência de brilho em determinadas notas. Para essa sala, é apropriado fazer uma palheta que tenha pouca vibração, tirando muito material de suas laterais, mas que resista ao mesmo tempo à ação refrigeradora do ar condicionado, que atua fechando a palheta. A fim de evitar a oclusão da palheta, mantém-se uma coluna proeminente no centro da mesma e mais material atrás do raspado, porém com uma meia lua que esteja bem destacada da casca. Ledet sustenta o modo de adaptar-se o raspado à acústica de uma sala viva escrevendo que:

A reverberação é o rolar contínuo do som e pode ser benéfico ou prejudicial para o timbre. Ceralmente, muita reverberação (sala viva) vai exigir do oboísta uma palheta com um som mais escuro enquanto que menos reverberação (sala seca) vai cortar muitas parciais e vai exigir que ele faça uma palheta mais clara. $\bigcirc$ ajuste de um jeito ou de outro vai interferir levemente a orientação sob a qual ele se baseia para raspar sua palhetal' (2008, p. 49).

10 Admittedly, when the oboist is actually playing, it is doubtful that he has any real selective control over some of the above acoustical phenomena. But he can recognize the presence of them and, thought this, perhaps encourage greater resonance in certain areas through modification of reeds and tone production. (tradução nossa)

11 Reverberation is the continuing roll of sound and can be beneficial or detrimental to timbre. [...] Generally, to much reverberation (live room) will cause the oboist to make a darker sounding reed while too little reverberation (dead room) will cut out too many partials and cause him to make a brighter sounding reed. The adjustment either way would effect a slight change in the way he cut his reed. (tradução nossa) 


\section{Pressão barométrica}

A pressão barométrica mede o peso da atmosfera e está intrinsecamente ligada a altitude. Ou seja, quanto maior a altitude mais as moléculas de ar se expandem e estão em menor quantidade interferindo diretamente na medida da pressão atmosférica. Em localidades de baixa altitude, as moléculas de ar estão mais próximas e em maior quantidade, aumentando a medida da pressão atmosférica. Em seu artigo para a revista The Double Reeds, Scarnati define a altitude de 4000 pés (1219,2m) como sendo a limítrofe, ou seja, subindo a partir desse ponto podemos considerar que estamos em zona de alta altitude.

Tocar e cantar em altitudes elevadas requer abordagens especiais para a preparação e realização. Simplificando, quanto maior a altitude - menos atmosfera existe. Definiremos a altitude elevada como níveis 4000 "e acima, embora se possa sentir diferenças a qualquer mudança de altitude $[\ldots]^{12}(1995$, p. 1).

No caso das palhetas de oboé, observou-se que quanto maior a pressão atmosférica mais facilmente elas vibrarão, sendo o contrário também verdadeiro, ou seja, quanto menor a pressão atmosférica, mais dificilmente as palhetas vibrarão. Isso se observa na prática, em cidades ao nível do mar onde há maior quantidade de moléculas de ar, as palhetas vibram muito facilmente. Em cidades em altitudes elevadas, onde $O$ ar é rarefeito, as palhetas tendem a não vibrar. Young Rennick constata que:

A pressão barométrica é uma medida do peso da atmosfera. Como tal, a pressão barométrica diminui com os aumentos de altitude. [...] Quando a pressão barométrica é alta, a palheta vibrará mais fácil, embora esta variação nas medidas seja muito mais sutil quando se viaja para uma

12 Playing and singing at high altitudes require special approaches to preparation and performing. Simply put, the higher the altitude-the less atmosphere there is present. We will define high altitude as levels 4000' and above, although one may sense differences at any change in altitude [...]. (tradução nossa) 
área de baixa elevação. ${ }^{3}$ (2010, p. 40-4 1).

Em cidades de altitude, notam-se dois fatores imediatos com as palhetas de oboé: elas se secam e se fecham. Young Rennick (2010) comenta a diminuição de umidade dizendo que "à medida que você viaja em uma área de maior altitude, a pressão atmosférica ou barométrica diminui e é provável que você experimente menos umidade" (p. 38). A palheta seca, não vibra porque ela permanece inflexivel, endurece como se fosse concebida com outro material. Há um relato interessante da oboísta americana Scarnati para a revista The double reeds contando que sua palheta se secou enquanto estava tocando uma frase:

A primeira vez que toquei um concerto em 7000 pés (2133 metros) eu cheguei perto do final de uma longa passagem quando a cana quase parou de tocar porque ela tinha realmente secado enquanto eu estava tocando! ${ }^{14}$ (1995, p. 1).

Scarnati menciona, ainda, as transformações que ocorrem na palheta decorrente da alta altitude e da baixa pressão atmosférica e cita que, além de se tornarem secas, se fecham.

Para nós que fazemos performances em altitudes elevadas, notamos menos oxigênio, atmosfera mais seca, menos ar disponivel para mover-se, e - para os instrumentistas de palhetas - a falta de vibração e palhetas fechadas ${ }^{15}$ (1995, p. 1).

13 Barometric pressure is a measure of the weight of the atmosphere. As such, barometric pressure decreases with increases in altitude. [...] When the barometric pressure is high, cane will vibrate easier, although this measurement is much more subtle than traveling to an area of lower elevation. (tradução nossa)

14 The first time that I played a concerto at 7000' I got near then end of a long passage and the reed almost stopped playing because it had actually dried out as I was playing! (tradução nossa)

15 For those of us performing at high altitudes, we notice less oxygen, drier atmosphere, less air available to move, and-for reed players-non-vibrating, closed reeds. (tradução nossa) 
A palheta fechada não tem possibilidade de vibrar porque as lâminas que a compõem estão encostadas umas nas outras, causando a oclusão da passagem de ar.

Uma vez que a palheta seca, é incapaz de vibrar por estar inflexivel e quando fechada, não vibra por impedir a passagem do ar. Conclui-se que a baixa pressão atmosférica ocasionada pela ação da alta altitude é um dos fatores que mais interfere em uma palheta de oboé, já que esta produz uma combinação exata capaz de fechar e secar a palheta, para que nenhuma nota saia do instrumento quando posto a tocá-lo sob tal condição.

Deve-se considerar também outro fenômeno que antecede as chuvas. Quando um barômetro indica que a pressão atmosférica está baixa, é sinal que haverá chuva. Este fenômeno é plenamente perceptivel com as palhetas de oboé, pois há uma mudança de atitude sempre quando o tempo está mudando. Pode-se, por exemplo, perder uma palheta ao raspá-la em tais condições climáticas. Passado o temporal, a palheta não será mais a mesma. Young Rennick (2010) cita em seu artigo a conclusão de Klimko para essa situação:

Klimko concluiu que há uma observação comum entre os feitores de palhetas quando diz: "Eu aprendi há muito tempo a não trabalhar em palhetas em dias de rápidas mudanças na pressão barométrica, como dias chuvosos, etc; mas a esperar os dias estáveis de "alta pressão" para ajustar as "monstras." (KLIMKO, 1991 apud YOUNG RENNICK, 2010 , p. 40-41).

\section{A ação da umidade}

É notório que palhetas tendam a inchar em localidades próximas a rios, lagos, florestas densas e úmidas ou próximas à praia. Com maior umidade na cana, aumenta a sua elasticidade. Em tais localidades é

16 Klimko sums up a common observation among reed makers when he says, "I learned long ago not to work on reeds on days of rapid barometric pressure changes, such as rainy days, etc.; but to wait for those stable 'high pressure' days to fine tune the 'monsters'. (tradução nossa) 
possivel torcer levemente um pedaço de cana sem rompê-la, no entanto, ao efetuarmos a mesma ação em clima seco e a cana seca, ela trinca. Ceralmente, ao viajar entre localidades distantes é aconselhável manter dentro da caixa de palhetas uma tira de papel ou pedaço de esponja previamente umedecido para evitar que a palheta sofra grandes transformações. Dependendo da localidade, se for em região muito seca, esta ação previne a palheta de trincar espontaneamente.

As caixas de palhetas umidificadas são usadas às vezes para impedir a deformação que pode ocorrer se uma palheta secar demasiadamente rápido. Em climas extremamente secos, a palheta pode realmente secar enquanto se toca. Dito isso, se um pedaço de cana se seca por causa da falta de umidade, isso afetará a vibração da cana. ${ }^{17}$ (YOUNG RENNICK, 2010, p. 42).

As palhetas que são feitas em lugares úmidos, como regiões próximas a lagos, rios, e cidades de praia vibram muito facilmente. A cana se comporta sem haver muita variação, permanecendo estável durante muitos dias. Young Rennick (2010) cita em seu artigo que: "Na maioria dos casos, os instrumentistas de palhetas sentem que as áreas com mais umidade têm palhetas que vibram mais facilmente". 8 (p. 42)

Posto isto, observa-se que se há uma palheta que não está vibrando muito bem em São Paulo, por exemplo, ela não deve ser rejeitada, mas sim reservada, pois um dia poderá ser útil e usada no momento certo, como em dias chuvosos ou em performances nas cidades próximas a lagos, grandes rios ou em localidades próximas ao mar.

17 Humidified reed cases are sometimes used to prevent warping, wich can occur if a reed dries out too quickly. In extremely dry climates reed can a actually dry out while he played. This said, if a piece of "dry" cane because of the humidity, it would affect the vibration of the cane. (tradução nossa)

18 In most instances reed makers feel that areas with more humidity have easier vibrating reeds. (tradução nossa) 


\section{A ação da temperatura}

Alterações também acontecem na palheta quando se toca em ambiente demasiadamente quente ou frio. Os extremos de temperatura logo são percebidos pelo oboísta devido a mudanças na maneira de vibrar da palheta. Percebe-se claramente esse fator em ambientes climatizados, através do uso do ar condicionado ao mudar de configuração para oferecer uma temperatura mais quente ou mais fria. Não podemos deixar de citar também, a ação do aquecimento causado por um conjunto desbalanceado das lâmpadas que iluminam o palco. Aquecendo-se o ambiente do palco, as fibras da palheta sofrem alterações decorrentes do aumento de temperatura $e_{\text {, }}$ consequentemente, ocorrerá uma dilatação das mesmas ocasionando uma abertura na palheta que finalmente, terminará por endurecê-la. Outro fator gerado pelo aquecimento é o ressecamento da palheta, impedindo-a de vibrar corretamente. No parágrafo sobre a interferência da acústica (p. 7), foi citado o devido procedimento para contornar o problema em tocar em uma sala viva, como é o caso da Sala São Paulo, Se de da OSESP. Vale lembrar: tira-se o material excedente das colunas laterais da palheta mantendo mais cana no centro e atrás do raspado, procurando, assim, minimizar um excesso de vibração da palheta $e$, ao mesmo tempo, preservar sua abertura. Ocorrendo um aumento na temperatura do ar condicionado que climatiza a Sala São Paulo, esta configuração de raspado já não será mais válida, pois a palheta endurece demasiadamente. Em tais circunstâncias, é adequado ajustar rapidamente a palheta de forma que esta fique menos aberta e menos dura. Não podemos deixar de notar, através desse exemplo, como sua matéria prima é sensivel e inconstante. Blais comenta sobre esse problema:

Tanto com cana pré-processada quanto com palhetas concluídas, a inconsistência é um problema. Como qualquer instrumentista de palheta dupla sabe, pequenas mudanças no clima, umidade e temperatura podem causar mudanças significativas na qualidade de uma palheta; e como sabem aqueles que fazem palhetas, a própria cana é um material altamente variável por causa de sua natureza orgânica. É muitas vezes provável que um pedaço de cana tomado de um punhado de canas produzirá uma boa palheta, como também é possivel que produza lixo, e pode ser difícil dizer 
o que ocorrerá de antemão. ${ }^{19}$ (2011, p. 9-10).

\section{Estudo comparativo dos ajustes propostos por oboístas brasileiros e suas escolas}

Para prosseguirmos com este estudo, é muito relevante observar um fenômeno característico dos naipes de oboés componentes das orquestras brasileiras. Oboístas de escolas diferentes convivem lado a lado e desempenham muito bem seus papéis como instrumentistas. Isto não é muito comum em países da Europa e um fato impensável nos Estados Unidos, país onde o oboísta francês Marcel Tabuteau (1887-1966) criou uma maneira bem particular de raspar a palheta, procurando suprir suas próprias necessidades como músico de orquestra. Vale ressaltar que ele criou uma mentalidade não somente dirigida à questão da flexibilidade, mas também mudou significativamente o timbre do oboé com seu novo raspado de palheta. Embora Tabuteau tenha discípulos espalhados pelo mundo afora, nem todos concordaram em seguir suas preferências de sonoridade e timbre. Foi criticado em sua época por outros oboístas que, assim como ele, eram radicados nos Estados Unidos. Como podemos ver nesta entrevista de Ledet com o famoso oboísta francês Fernand Gillet:

Você observará que, de acordo com os atuais instrumentistas de oboé na América, essas palhetas serão chamadas de antiquadas. No entanto, para estes que gostam de ter um som entre um saxofone e uma clarineta, estão confundindo uma sonoridade que seja ressonante, com um som sujo de palheta. É como se você colocasse um silenciador num belo violino Stradivarius 20 (LEDET, 2008, p. 127).

19 Both with pre-processed cane and completed reeds, inconsistency is a significant problem. As any double reed player knows, slight changes in weather, humidity, and temperature can cause significant changes in the quality of a reed; and, as reedmakers know, cane itself is a highly variable material because of its organic nature. A piece of cane taken from a pile is often just as likely to produce a good reed as it is to produce garbage, and it can be difficult to tell which will occur beforehand. (tradução nossa)

20 You will notice that, according to the present oboe players in America, these reeds will be called old-fashioned. They are, however, confusing a ringing tone with a reedy tone, for they like to have a tone something between a saxophone and a clarinet. It is just as if you put a muffler on a beautiful Stradivarius violin. (tradução nossa) 


\section{Sonoridade, Flexibilidade e Timbre}

Mediante esses fatos, foi realizado um estudo comparativo a fim de identificar quais elementos são determinantes aqui no Brasil, onde as escolas proeminentes, a Alemã e a Americana, convivem lado a lado, sem que haja diferenças significativas em relação ao timbre e à sonoridade.

Procurou-se então, abordar algumas perguntas sobre sonoridade, flexibilidade e timbre. Colocou-se como peça de referência os Três Romances Opus 94 de Robert Schumann, peça usual de repertório, para que o entrevistado tivesse em mente algo concreto no qual pudesse apoiar-se para as suas respostas.

Após a coleta dos resultados, alguns gráficos comparativos foram concebidos, com o intuito de melhor a visualização dos dados coletados.

Considerou-se flexibilidade segundo dicionário on-line Google: 1 - qualidade do que é flexível, maleável. 2- facilidade e ligeireza de movimentos; agilidade, elasticidade, elegância. 3- propriedade do que é dócil ao manejo; maleabilidade. 4- brandura, docilidade.

Considerou-se timbre, segundo o dicionário on-line Coogle: 1qualidade sonora de instrumento ou voz. 2- som claro, harmonioso, suave, agradável ao ouvido. 3- propriedade que têm certos corpos de emitir sons intensos ou sons de frequência regular. 4- propriedade, que apresentam certos corpos ou ambientes, de reforçar os sons. 5- uma das qualidades do som.

Considerou-se sonoridade, segundo o dicionário on-line Coogle: 1- som claro, harmonioso, suave, agradável ao ouvido. 2- som claro e nítido 'as s. de um carrilhão' 3-propriedade que têm certos corpos de emitir sons intensos ou sons de frequência regular. 4- propriedade, que apresentam certos corpos ou ambientes, de reforçar os sons; acústica.5uma das qualidades do som. 


\section{Gráficos Comparativos - Sonoridade, Flexibilidade e Timbre}

Neste gráfico, observamos que a flexibilidade é importante. Oboístas de Escola Alemã ainda pensam em som:
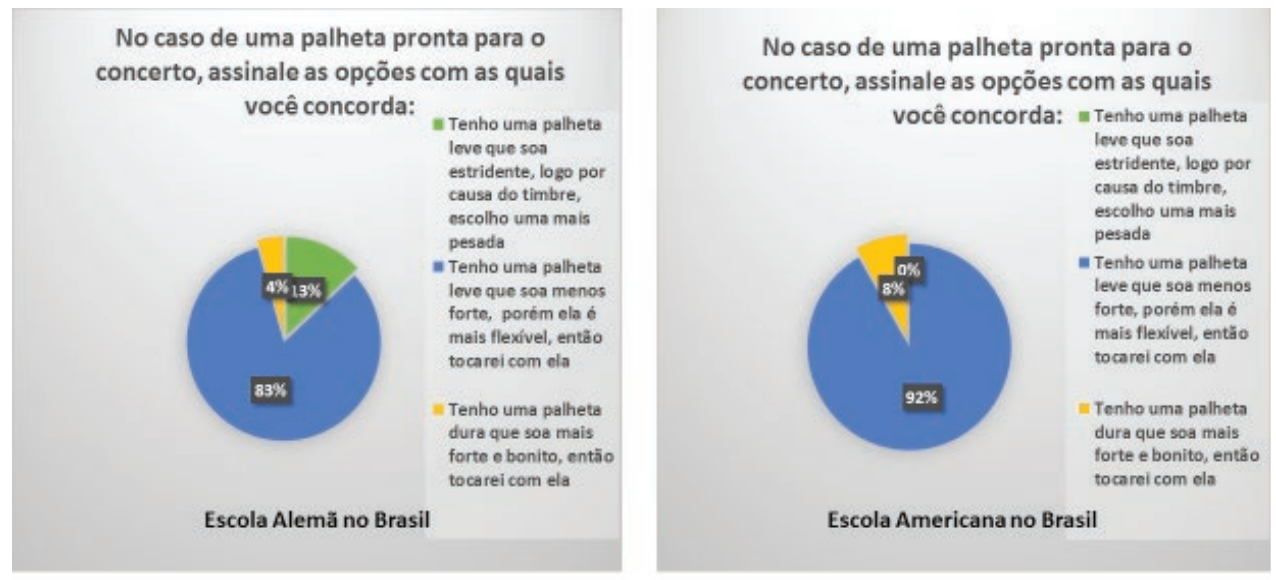

De acordo com os gráficos, usando-se o termo "Concerto" ambas as escolas preferem palhetas que sejam flexiveis, apesar delas soarem menos.

Oboístas da escola alemã ainda tendem a pensar mais em sonoridade.

Gráfico 1: Timbre, Flexibilidade e Volume Sonoro numa situação de concerto.

Fonte: Elaborado pelo autor, criados pelo programa de pesquisa on-line, survey monkey.

Já no gráfico seguinte, acontece uma peculiaridade: enquanto os oboístas de escola americana preferem uma palheta boa, os de escola alemã pensam em sonoridade. 

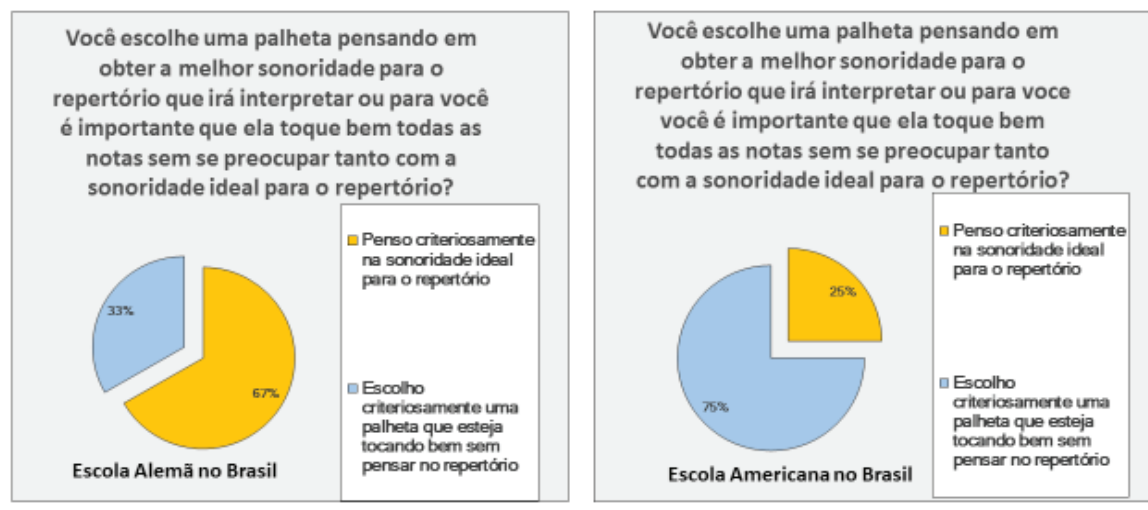

Nestes gráficos, em caso de repertório, os oboístas com Escola Alemã dão preferência à sonoridade enquanto oboístas com a Escola Americana preferem uma palheta que esteja boa.

Gráfico 2: Sonoridade versus conforto em situação de repertório (A expressão "palheta que toque bem sugerindo sensação de conforto').

Fonte: Elaborado pelo autor, criados pelo programa de pesquisa on-line, survey monkey.

No gráfico seguinte, a maioria concorda em utilizar uma palheta para a função que será exercida:
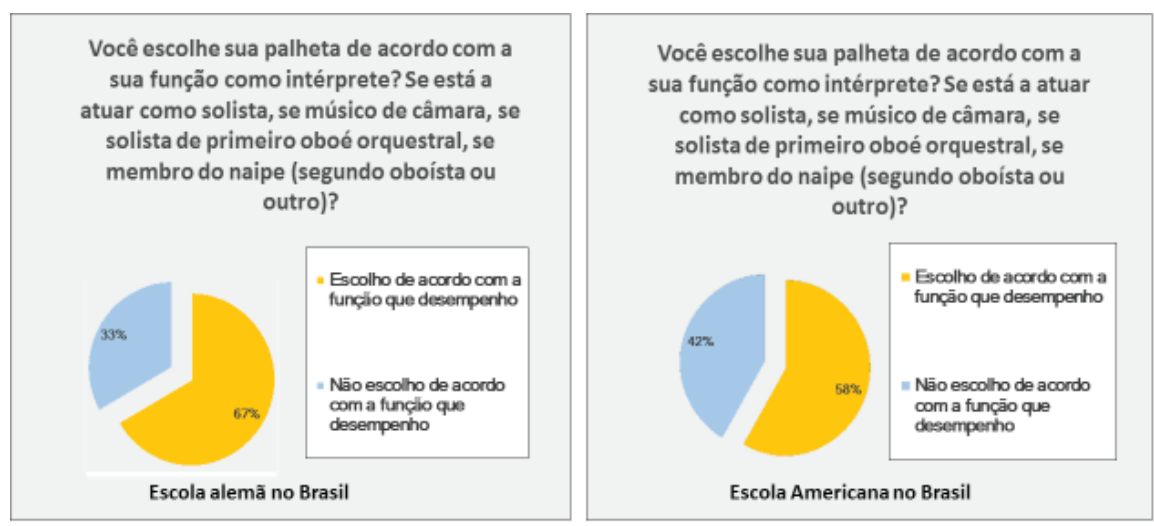

De acordo com os gráficos, ambas as escolas escolhem a palheta adequada para a função a desempenhar.

Gráfico 3: Escolha da palheta para uma determinada função.

Fonte: Elaborado pelo autor, criados pelo programa de pesquisa on-line, survey monkey.. 
Observamos nos gráficos abaixo um fator que pode ser determinante: ambas as escolas continuam a preferir flexibilidade, mas neste caso, enquanto os de palheta alemã preferem a dinâmica piano em segundo lugar, os de palheta americana preferem o timbre escuro, colocando a dinâmica por último.

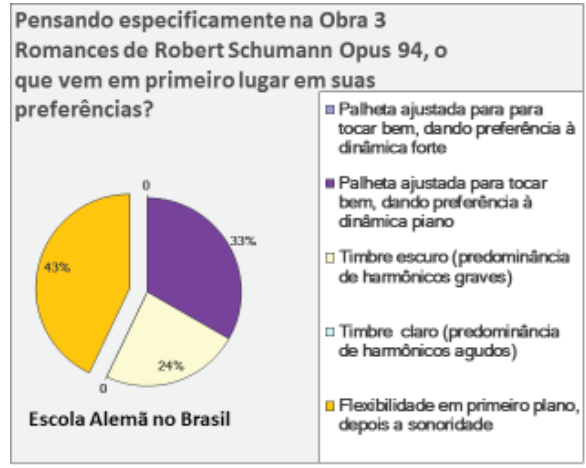

Oboístas com Escola Alemã escolheram: Flexibilidade - Dinâmica piano -Timbre escuro.

Não houve quem optasse pela dinâmica Forte.

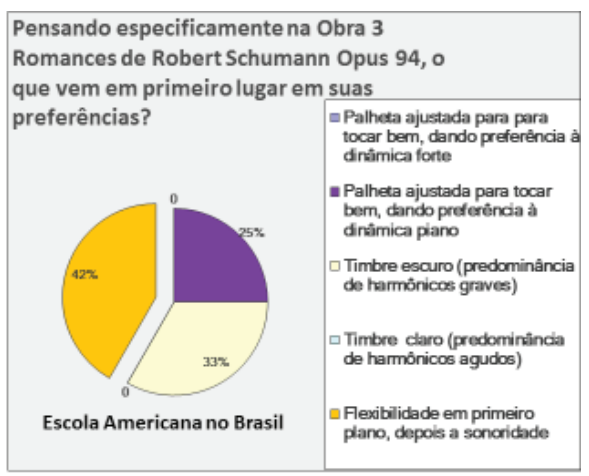

Oboístas com escola americana escolheram: Flexibilidade -Timbre escuro - Dinâmica piano.

Não houve quem optasse pela dinâmica Forte.

Gráfico 4: Escolha da palheta para repertório específico. Listagem por ordem das preferências de características quanto à flexibilidade, dinâmica e timbre.

Fonte: Elaborado pelo autor, criados pelo programa de pesquisa on-line, survey monkey..

No próximo gráfico, a maioria dos oboístas preferiu uma palheta que tocasse normalmente, sem pensar em repertório. Para aqueles que responderam que preparavam a palheta de forma diferente, houve uma investigação já que esta pergunta permitia uma resposta por escrito. Concluiu-se que procuravam a flexibilidade. 


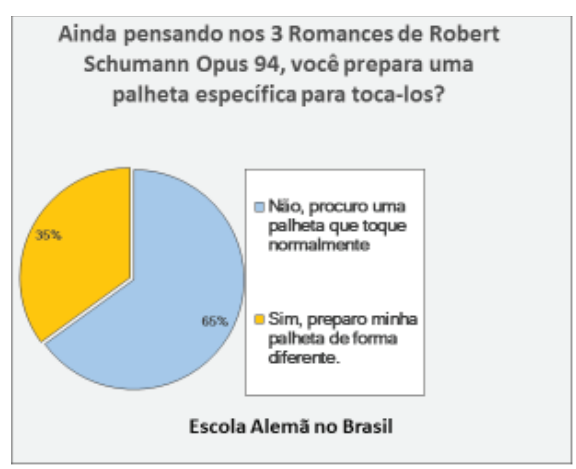

De acordo com o gráfico, oboístas com Escola Alemã escolhem uma palheta que toque normalmente. Porém houve uma parcela maior (do que americanos) que escolheu preparar sua palheta.
Ainda pensando nos 3 Romances de Robert Schumann Opus 94, você prepara uma palheta especifica para toca-los?

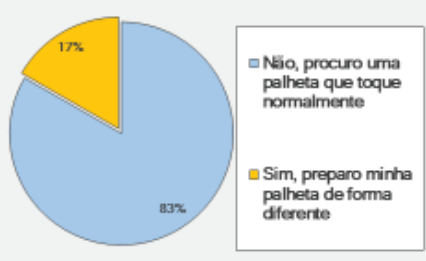

Escola Americana no Brasil

De acordo com o gráfico, oboístas com Escola Americana escolhem uma palheta que toque normalmente. Houve uma parcela menor (do que alemães) que escolheu preparar sua palheta.

Gráfico 5: Preparo de uma palheta para repertório específico.

Fonte: Elaborado pelo autor, criados pelo programa de pesquisa on-line, survey monkey.

Nessa primeira seção de gráficos comparativos, percebe-se que ambas as escolas dão preferência à flexibilidade e a uma palheta que toque bem. ${ }^{21}$ De acordo com os gráficos da seção 2, os oboístas de escola alemã tendem em pensar na sonoridade. Porém, nos gráficos da seção 4, os de escola americana preferem a sonoridade ao invés da dinâmica em piano, sendo que os oboístas de escola alemã surpreenderam ao dar maior importância à dinâmica piano. $\bigcirc$ resultado dessa primeira parte da pesquisa segue satisfatório na seguinte direção:

Uma palheta com excelente sonoridade geralmente é menos flexivel, o que corresponde a ter uma maior dificuldade na emissão das notas na dinâmica "piano". A escola alemã até o momento indica dar maior importância à sonoridade. Logo, isso sugere que a palheta seja menos flexivel e a dinâmica piano mais difícil. Mas, quando uma das perguntas foi direcionada em relação à preferência, os oboístas da escola alemã fizeram o contrário, preferindo a dinâmica piano ao invés da sonoridade. Por outro lado, a escola americana demonstra que dá mais importância à flexibilidade do que à sonoridade. Dessa maneira, há mais facilidade na emissão das notas na dinâmica "piano". Porém, quando a questão abordada foi através da preferência, os oboístas

21 Considerou-se uma palheta que toque bem, aquela que emite todas as notas do oboé com facilidade, com a afinação adequada, tenha sonoridade agradável à maioria dos ouvintes e reproduza fielmente as dinâmicas e articulações propostas pelo intérprete. 
da escola americana não deram tanta importância à dinâmica "piano", preferindo, por sua vez, a sonoridade. Embora se pareça com uma ação contraditória de ambas as partes, essa análise ajuda-nos a concluir que "ambos procuram a flexibilidade com uma sonoridade que thes seja ideal dentro das particularidades que suas escolas de raspagem oferecem".

\section{Ajustes}

A pesquisa preocupou-se ainda por investigar a existência de semelhanças nos ajustes das palhetas de oboé em ambas as escolas. Veremos a seguir, uma simulação de uma série de situações adversas pelas quais os oboístas passam no decorrer de uma jornada de trabalho. Serão apresentados, também, os agentes climáticos causadores das variações no comportamento de uma palheta. Em seguida, um levantamento de ajustes conhecidos nas palhetas será proposto. Serão apresentadas duas imagens de palhetas representando as duas escolas predominantes no Brasil. Letras estarão identificando cada região de ajuste na palheta. Por último, será feita uma comparação do tipo de ajuste que é feito pelas escolas, procurando investigar a existência de algum padrão de ajustes e se todos se utilizam da mesma técnica para contornar as variações climáticas. Vale relembrar que as perguntas foram feitas de forma clara e objetiva, com o jargão utilizado pelos oboístas, tendo como objetivo levar à mente do entrevistado a sensação de estar passando pela adversidade que requer um ajuste em sua palheta naquele exato momento.

\section{Leitura dos gráficos}

Nos gráficos seguintes, o eixo vertical representa o número de entrevistados que responderam às questöes. Já o eixo horizontal representa os ajustes propostos. Cada coluna no eixo horizontal representa um ajuste, indicado por uma letra abaixo. Toda coluna fica maior ou menor de acordo com o número de pessoas que as escolheu. A numeração do eixo vertical acompanha a coluna que tiver maior número de escolhas, estando sempre um número acima. Ou seja, se 8 entrevistados escolheram a coluna "ajuste na ponta", e este foi o ajuste preferido pela maioria, o eixo vertical terminará em 9. 


\section{Gráficos Comparativos - Ajustes}
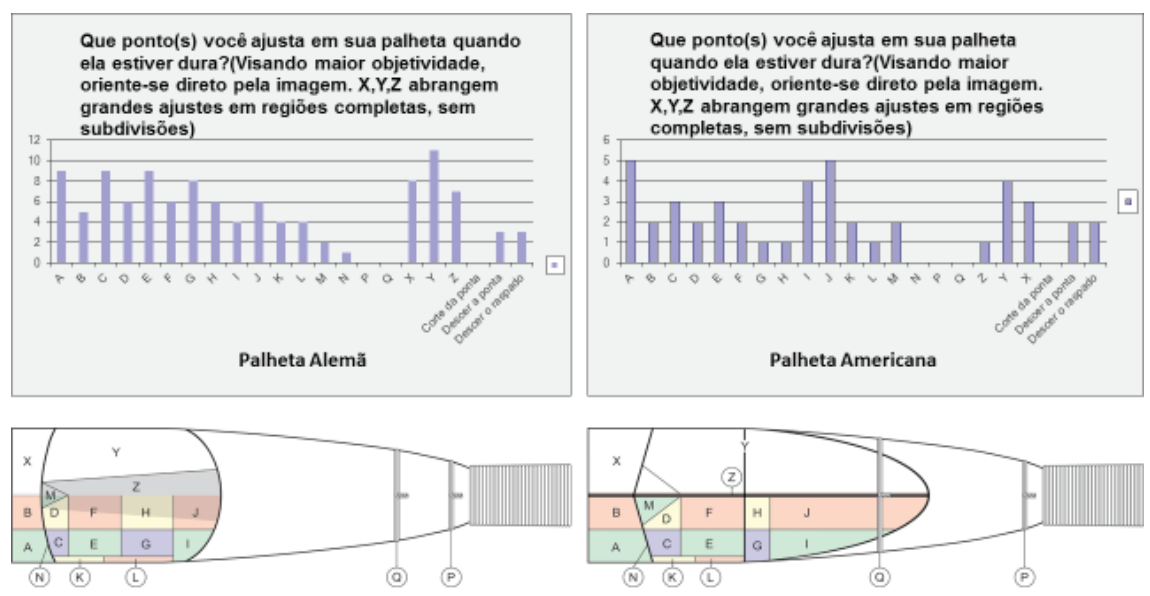

De acordo com os gráficos, estando a palheta dura, os ajustes das escolas são quase idênticos
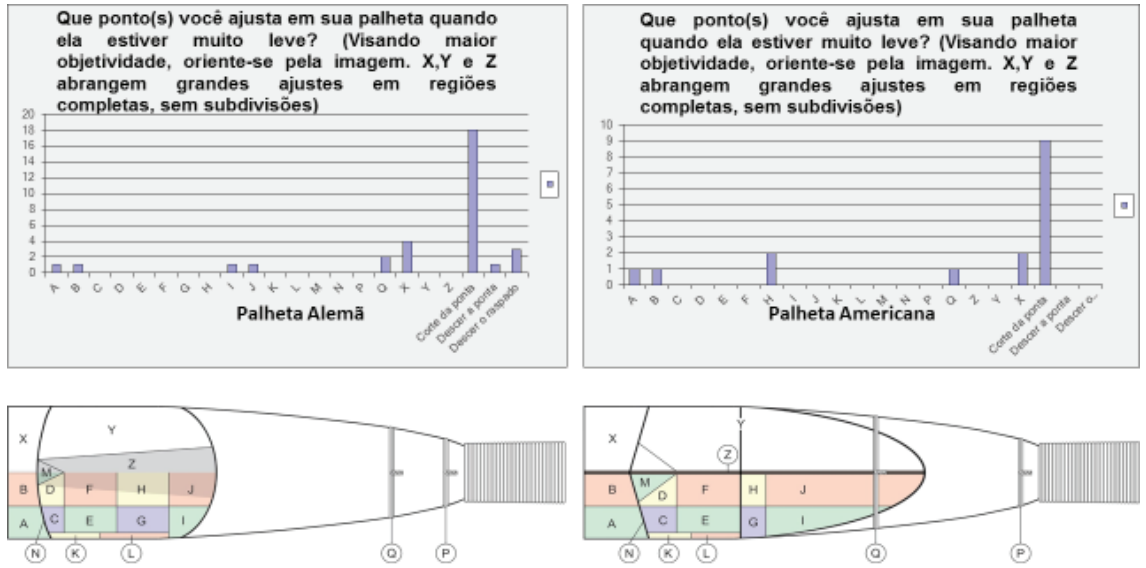

Os ajustes se assemelham: corte da ponta, ajuste da ponta $\mathbf{A} \mathbf{B}$ e $\mathbf{X}$ e abrir com arame $\mathbf{Q}$.

Gráfico 6: Ajustes de raspagem visando contornar problemas de flexibilidade.

Fonte: Elaborado pelo autor, criados pelo programa de pesquisa on-line, survey monkey. 

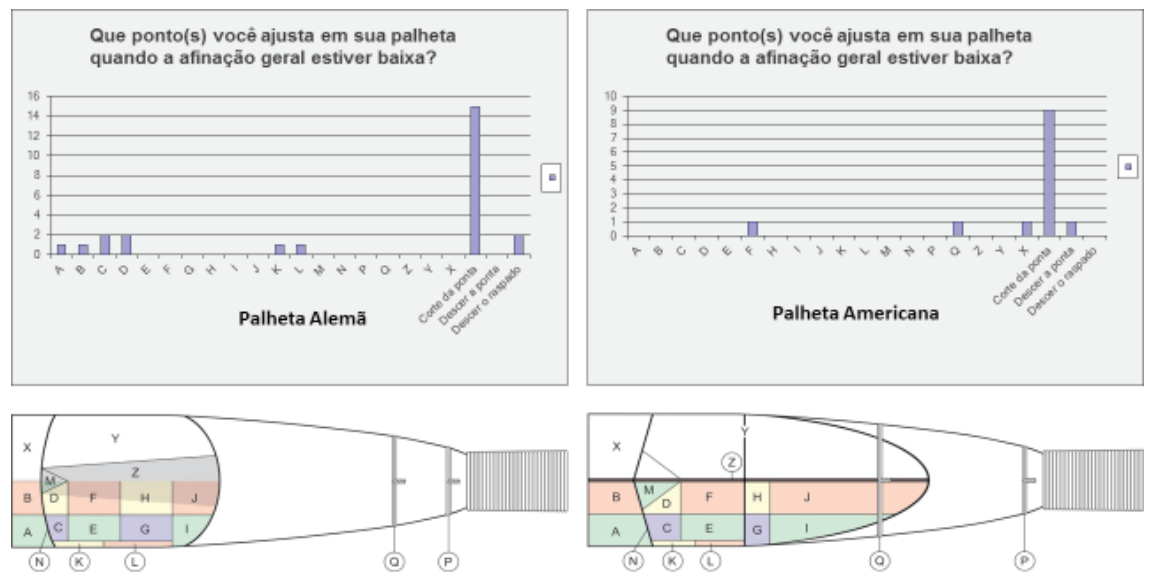

Observa-se grande semelhança na opção quase unânime do corte de ponta. Alguns ajustes aparecem, porém mais na escola alemã, nas regiões $\mathbf{A B}$ (ponta) e $\mathbf{C D}$ (atrás da ponta).
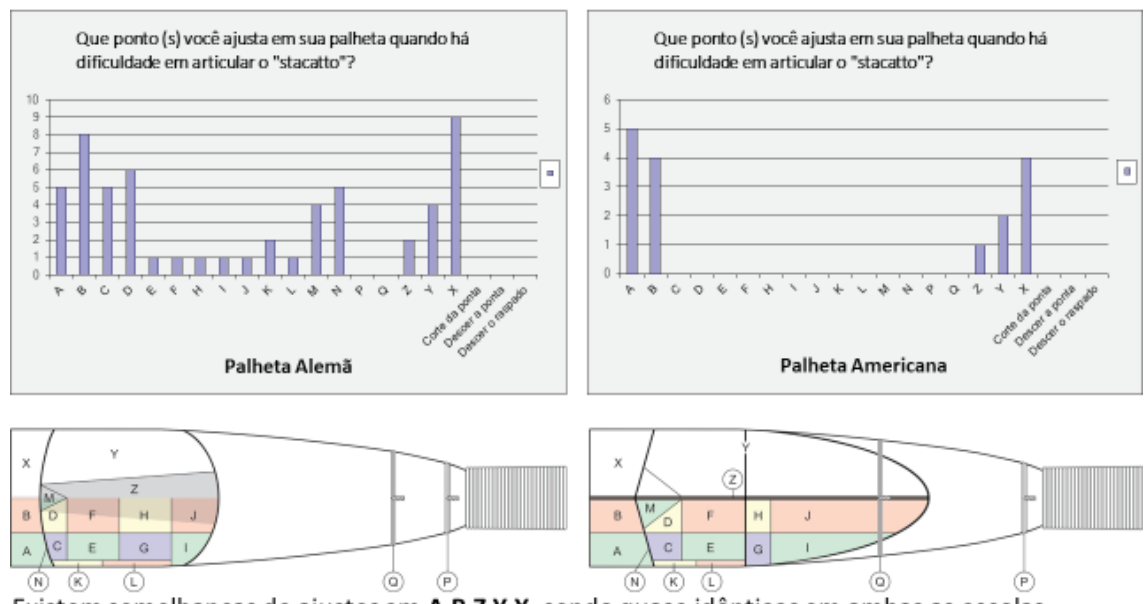

Existem semelhanças de ajustes em A B Z Y X , sendo quase idênticos em ambas as escolas.

Porém predominam ajustes na escola alemã.

Gráfico 7: Ajustes de raspagem visando contornar problemas interpretativos.

Fonte: Elaborado pelo autor, criados pelo programa de pesquisa on-line, survey monkey. 

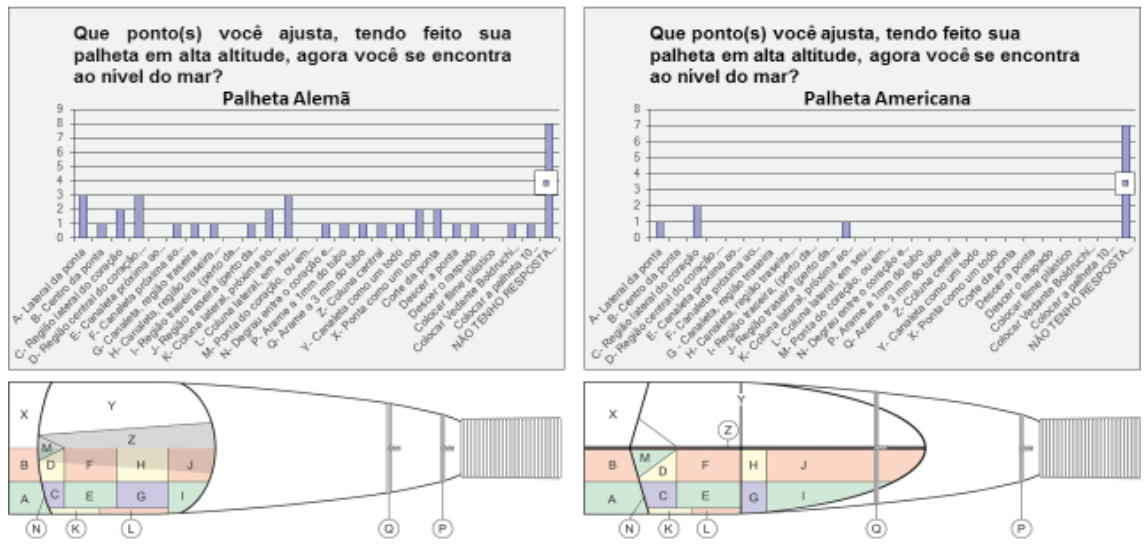

A opção "não tenho resposta para a questão" foi a mais escolhida por ambas as escolas. Predominam ajustes na escola alemã em quase toda a palheta, enquanto que na escola americana há poucos que ajustam A C K.
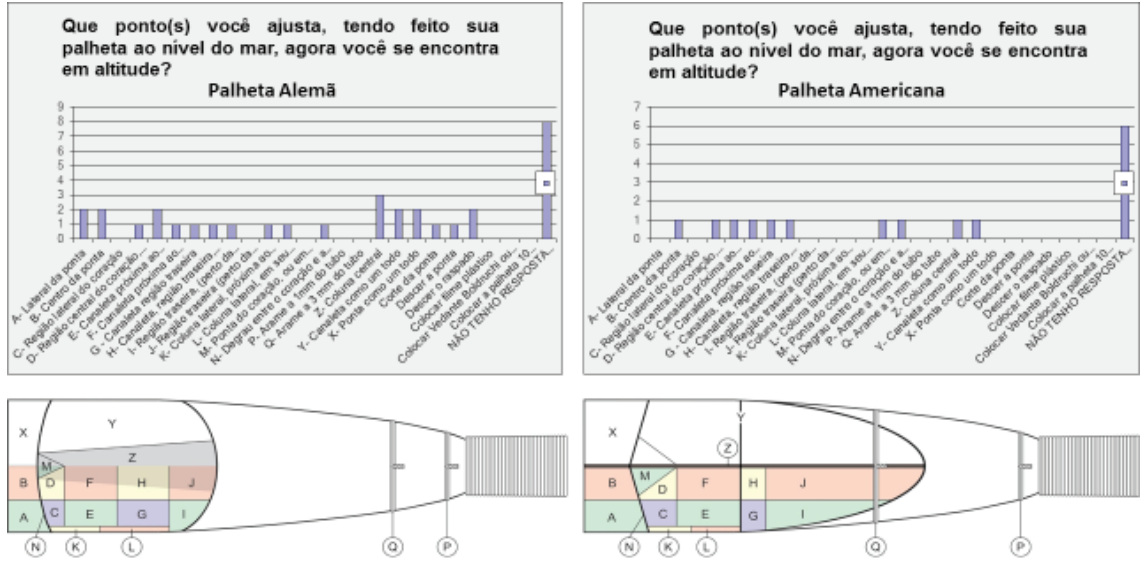

A opção "não tenho resposta para esta questão" foi a mais escolhida por ambas as escolas.

Poucos ajustes foram detectados. Predominam ajustes na escola alemã.

Gráfico 8: Ajustes de raspagem visando contornar problemas causados pela pressão atmosférica. Fonte: Elaborado pelo autor, criados pelo programa de pesquisa on-line, survey monkey. 

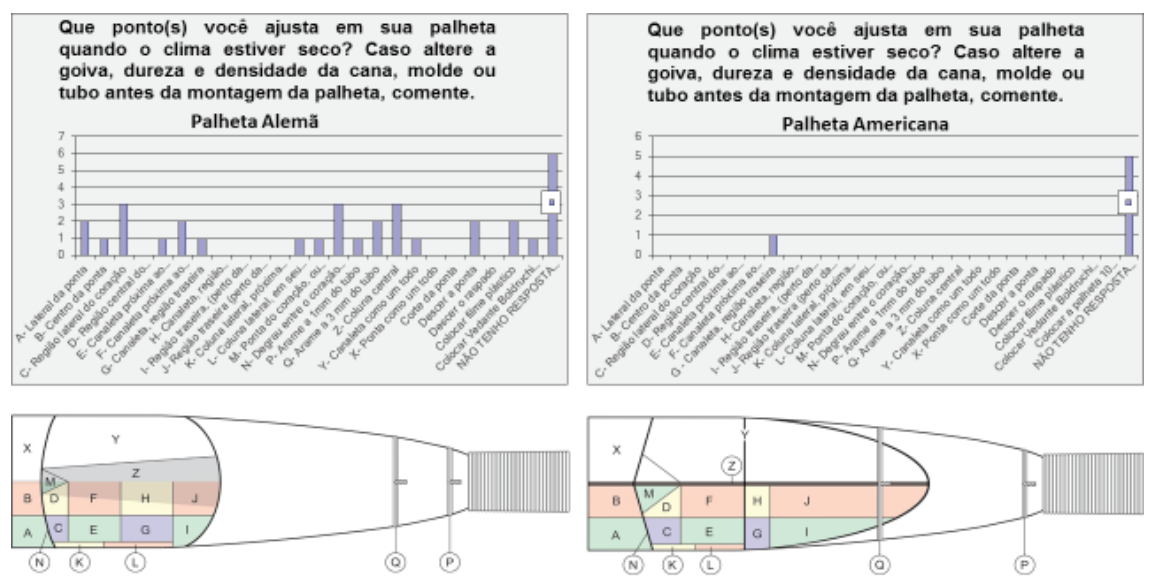

A opção "não tenho resposta para esta questão" foi a mais escolhida por ambas as escolas. Predominam ajustes na escola Alemã.

Gráfica 9: Ajustes de raspagem visando contornar problemas causados por fatores climáticos:

Fonte: Elaborado pelo autor, criados pelo programa de pesquisa on-line, survey monkey.

De acordo com a leitura dos gráficos comparativos acima, pudemos observar o que se segue:

1. Há muitas semelhanças nos tipos de ajustes escolhidos pelos representantes das duas escolas. $\bigcirc$ que nos leva a concluir que há grande similaridade nos pontos de ajustes que, nesta pesquisa, foram proporcionalmente transferidos de uma escola para a outra.

2. Os oboístas adeptos à raspagem da escola alemã escolheram, nessa pesquisa, um maior número de ajustes para cada problema apresentado, enquanto que os oboístas adeptos da escola americana fizeram menos ajustes para o mesmo fator. Pode-se concluir que, devido ao tamanho menor da área de raspagem, a palheta alemã é muito mais sensivel às variações necessitando um maior número de ajustes para cada fator apresentado. Logo, a palheta de escola americana, por possuir uma maior área de raspagem, é mais flexivel por si só, não precisando de tantos ajustes para que os problemas apresentados sejam corrigidos. 
3. Quando se tratou dos fatores climáticos, que efetivamente produzem as alterações nas palhetas, como vimos anteriormente, a maioria dos oboístas entrevistados não souberam responder às questões elaboradas. No entanto, houve uma manifestação maior na escolha de ajustes por parte dos oboístas adeptos da raspagem de escola alemã. Concluímos que os oboístas entrevistados nessa pesquisa, não fazem um trabalho preventivo no que tange às variações climáticas e da pressão atmosférica. $\bigcirc$ que é ajustado pela maioria dos oboístas entrevistados é a variação na palheta decorrente dos fatores externos, que acontece imediatamente no momento que antece de uma performance, não havendo em sua maioria qualquer ação preventiva ao procurar impedir, de certa forma, que a palheta sofra grandes alterações devido a fatores externos que, como já visto, podem ser previstos. Preferem trabalhar através da compreensão dos seus estímulos sensoriais adquiridos no momento da adversidade a trabalhar com aquilo que efetivamente causa a adversidade. 


\section{Considerações Finais}

Vimos nesse trabalho, a descrição minuciosa daquilo que ocupa a maior parte do tempo da rotina de um oboísta: os ajustes nas palhetas decorrentes das variações climáticas. Houve uma abordagem do tema sob a ótica do território nacional, querendo investigar se são esses ajustes que fazem com que diferentes escolas coexistam lado a lado dentro do ambiente orquestral. Investigaram-se também, as preferências de sonoridade e flexibilidade como fatores causadores dessa particular convivência das diferentes escolas.

Como pudemos ver na leitura dos gráficos, houve uma aparente contradição por parte dos oboístas entrevistados, quando submetidos a algumas questões investigativas com mesmo sentido, mas elaboradas de forma diferente. Perguntou-se sobre timbre, sonoridade, flexibilidade, dinâmica, repertório, tipo de função a ser exercida e, finalmente, o preparo de uma palheta diferenciada para uma obra específica. Concluiuse, porém, que ambas as escolas representadas estão à procura do mesmo objetivo através de sua palheta: sonoridade agradável aliada à flexibilidade. Isto é o resumo, daquilo que um oboísta brasileiro, não importando a escola, considera ser uma "boa palheta".

Em seguida, essa pesquisa investigou a existência (ou não) de algum padrão de ajuste nas palhetas dos oboístas entrevistados. Abordaram-se questões que resolvessem problemas de flexibilidade, de interpretação, causados pela pressão atmosférica e, também, pelo clima. Conforme pudemos observar, os ajustes são extremamente parecidos $e_{\text {, }}$ aliado a isso, há um desconhecimento relacionado à causa que, por sua vez, pedem ajustes e às suas possíveis medidas de prevenção.

Portanto, é bem provável que essa semelhança de pensamentos e tendências entre os oboístas brasileiros, seja o determinante na convivência entre as diferentes escolas utilizadas pelos profissionais membros das orquestras no Brasil.

Esse trabalho carrega em si, a pretensão de abrir novas fronteiras de pesquisa na elaboração de material contendo: indicações sobre ajustes de palhetas, prevenções sob agentes climáticos e estudos que envolvam fenômenos sociológicos no núcleo de oboístas brasileiros. 


\section{Referências}

BACKUS, John G. Synthetic woodwind instrument reed and method for its manufacture. U.S. Patent n. 4,337,683 A, 6 jul. 1982. Disponivel em: <https://www.google.ch/patents/US4337683> Acesso em: 27 set. 2016.

BLAIS, Zachary Everett. Effects of Time on the Sound Quality of Cane Oboe Reeds. Tese de Doutorado. Worcester Polytechnic Institute, 2011. Disponivel em: <https://web.wpi.edu/Pubs/E-project/Available/Eproject-011911-112924/unrestricted/FINAL_IQP_REPORT.pdf>. Acesso em: 06 jan. 2017.

BLASCO-YEPES Carolina; PAYRI, Blas. The influence of reed making on the performance and sound quality of the oboe. Universidad Politécnica de Valencia, Spain, 2010. Disponivel em: <http://smcnetwork. org/files/proceedings/2010/5.pdf>. Acesso em: 27 set. 2016.

CARVALHO, Luiza Alves de. Metodologia qualitativa em pesquisa sobre formação de professores: narração de uma experiência. In: PERSPECTIVAS ONLINE, Campos dos Coytacazes, v. 1, n. 4, p. 9-24, 2007. Disponivel em: <http://seer.perspectivasonline.com.br/index.php/revista antiga/article/viewFile/269/180>. Acesso em: 27 set. 2016.

DELUNE, Léon. Le bois dans les industries de la musique. In: Économie et forêt. R .F .F. XXIX - 2, 1977. Disponivel em: <http://documents.irevues. inist.fr/bitstream/handle/2042/21128/RFF_1977_2_143.pdf>. Acesso em: 27 set. 2016.

DICIONÁRIO informal da língua portuguesa Google. Disponivel em: <http://www.dicionarioinformal.com.br/google/> Acesso em: 06 jan. 2017.

COSSENS, Léon; ROXBURGH, Edwin. Die Oboe. Edition: Sven Erik Bergh, $\mathrm{CH}, 1977$.

KAUFMANN, Jean-Claude. A entrevista compreensiva: um guia para a pesquisa de campo. Trad. Thiago de Abreu e Lima Florêncio; revisão técnica de Bruno Cesar Cavalcanti. Petrópolis, RJ: Vozes; Maceio, Al: Edufal, 2013.

LEDET, David A. Oboe Reed Styles. Indiana University Press, 2008. 
LACY, Edwin. An experiment in treatment of Arundo Donax, The Journal of the International Double Reed Society, n. 16, 1988.

ROCHA, Décio; DAHER, Maria Del Carmen; SANT'ANNA, Vera Lúcia de Albuquerque. A Entrevista em situação de pesquisa acadêmica: reflexões numa perspectiva discursiva. v. 8, n. 8 (2004). Disponível em: <http://periodicoscientificos.ufmt.br/ojs/index.php/polifonia/article/ view/1132> acesso em 23 ago. 2016.

SCARNATI, Rebecca Kemper. Oboe Reed Notes from Seven Thousand Feet. Double Reed 18/1 (1995): 75. Disponivel em: <https://nau.edu/ uploadedFiles/Academic/CAL/Music/Studio_Sites/Folder_Templates(4)/ High\%20Altitude\%20Performing.pdf>. Acesso em: 27 set. 2016.

YIN, Robert K. Estudo de caso: planejamento e métodos. Trad. Christhian Matheus Herrera. 5a. ed. Porto Alegre: Bookman, 2015.

YOUNG RENNICK, Elizabeth Ann. Oboe reed-making pedagogy. In: the United States: a survey. DMA (Doctor of Musical Arts) thesis, University of lowa, 2010. Disponivel em: <http://ir.uiowa.edu/cgi/viewcontent. cgi? article $=1817$ Econtext=etd>. Acesso em: 27 set. 2016 .

\section{Sobre o autor}

Joel Gisiger iniciou seus estudos de oboé em 1983, na Escola Municipal de Música de São Paulo, com o Professor Benito Sanches. Obteve aulas de aperfeiçoamento com Washington Barella. Em 1989 recebe, por concurso, uma bolsa de estudos pela Fundação Vitae para a Academia da Filarmônica de Berlim - Fundação Karajan - passando a ter aulas com o lendário Lothar Koch.

Como professor, participou do $X I X^{\circ}, X X^{\circ}$ e $X X X V I^{\circ}$ Festival Internacional de Música de Brasilia, de várias edições do Festival de Inverno de Campos do Jordão e do XXº Festival de Música de Londrina além de receber diversos convites para ministrar Máster Classes. É professor da Escola municipal de Música de São Paulo, do Instituto "Jovens Baccarelli" e da Academia da Osesp. Tem se apresentado como 
solista em diversas orquestras, destacando-se dentre muitas, a Orquestra Sinfônica de Santo André, a Orquestra de Câmara São Paulo, Orquestra Sinfônica de Ribeirão Preto, Orquestra Virtuosi e Orquestra Sinfônica do Estado de São Paulo, nessa última realizou a primeira audição Latino Americana do Concerto para Oboé de Alfred Schnittke. No exterior, Gisiger tocou como camerista no Castelo de Charlotenburg (Berlim), na Orquestra da Academia (Fundação Karajan) e no Quinteto de Sopros da Akademie des Berliner Philarmonischen Orchester, além de ter tocado na Filarmônica de Berlim em concerto sinfônico. Desenvolveu trabalho camerístico com o Quinteto de sopros de Curitiba apresentando-se em concertos nas cidades de Stuttgart e Munique. Mantém atividade regular com o Quinteto de Sopros da Osesp, ministrando aulas e máster classes no interior do Estado de São Paulo e pelo Brasil. É primeiro oboésolo da OSESP onde atua desde 1988, posto que the rende criticas de destaque, tais como: "Joel Gisiger, há muito, merece o prêmio nacional do oboé, criado só para ele..." na Folha de São Paulo em 20/03/2003. Atualmente, é mestrando da PPCPROM-UFBA.

Recebido em 28/03/2017

Aprovado em 02/09/2017 